\title{
Trunk Strength Characteristics of Elite Alpine Skiers - A Comparison with Physically Active Controls
}

\author{
by \\ Carolin Hildebrandt ${ }^{1}$, Lisa Müller ${ }^{1}$, Christian Heisse ${ }^{1}$, Christian Raschner ${ }^{1}$
}

\begin{abstract}
Core muscle imbalances and weak trunk strength are relevant for injury prevention and performance. Information regarding core strength requirements and ideal flexion/extension ratios in alpine skiing is limited. We aimed to compare trunk strength capacities in elite alpine skiers with those of a matched control group. The concentric maximal trunk flexion and extension of 109 elite skiers and 47 active controls were measured at $150 \%$ in a ballistic mode using the CON-TREX® TP 1000 test system. The relative flexion peak torque was higher in male ski racers $(p=$ $0.003 ; 2.44 \pm 0.30 \mathrm{Nm} / \mathrm{kg})$ than in the controls $(2.32 \pm 0.42 \mathrm{Nm} / \mathrm{kg})$. The relative peak torque for extension was $4.53 \pm$ $0.65 \mathrm{Nm} / \mathrm{kg}$ in ski racers and $4.11 \pm 0.52 \mathrm{Nm} / \mathrm{kg}$ in the controls $(p=0.001)$. Female athletes were significantly stronger in both, relative flexion force ( $p=0.006$; skiers $2.05 \pm 0.22 \mathrm{Nm} / \mathrm{kg}$; controls $1.74 \pm 0.28 \mathrm{Nm} / \mathrm{kg}$ ) and relative extension force ( $p=0.001$; skiers $3.55 \pm 0.53 \mathrm{Nm} / \mathrm{kg}$; controls $3.14 \pm 0.48 \mathrm{Nm} / \mathrm{kg}$ ). No significant differences were found in the ratios of flexion to extension forces in females and males. Ski racers are engaged in extensive strength training for both leg and trunk muscles, which explains the higher peak values. Both groups indicated a low ratio from 0.54-0.59, which represents high trunk extensor muscles strength relative to flexor muscles.
\end{abstract}

Key words: alpine skiing, elite athletes, core strength, flexion/extension core ratio.

\section{Introduction}

Alpine skiers are characterised by a very specific and complete physiological profile (Hydren et al., 2013). Along with the anaerobic metabolism, leg and core strength is a predictor of performance (Neumayr et al., 2003). Alpine skiing is also influenced by external factors that require adaption by the athlete. Speed, movements and the direction of skiing change constantly, which creates challenging demands on the athlete's balance (Hintermeister et al., 1995). In particular, the core muscles are important to minimise alterations in the standing position. Good balance between strength and production of force is important for maintaining a central position on the skis when movements are performed at a high velocity. Irrespective of gender, appropriate core strength seems to be an especially critical factor for preventing knee injuries in competitive skiers
(Leetun et al., 2004; Raschner et al., 2012). Additionally, there is evidence that excessive competitive sports during youth and insufficient core stability provoke low back pain (LBP) (Schmidt et al., 2014). Reports indicate that LBP is a growing problem in alpine skiing and the aetiology of back pain in adolescent athletes is higher than in their older counterparts (Hildebrandt and Raschner, 2013; Young et al., 2011). Bergstrøm et al. (2004) reported that LBP was associated with intensive physical activities in $67 \%$ of skiers from high school. Insufficient core strength, inappropriate recruitment of the trunk muscles and imbalances of the core muscles may contribute to this problem. However, LBP has also been described for elite athletes. One of the most successful alpine skier could not participate in the Olympic Games during the

1 - Department of Sport Science, University of Innsbruck, Innsbruck, Austria. 
winter season 2013/2014. In this case, his medal hope disappeared because of herniated disc surgery. Yet, there is a lack of research investigating sport-specific core strength requirements and ideal flexion/extension ratios. Muscle imbalances of the core and weak trunk strength have been already noted for their relevance, not only in terms of injuries, but also in performance (Hibbs et al., 2008). A comparison of trunk strength in elite rowers and control subjects indicated that rowers were significantly stronger with a lower extensor-flexor ratio (Mc Gregor et al., 2004). In contrast, a study of Baur et al. (2010) revealed that maximum core strength of elite motor sport athletes did not differ from that of physically active controls. To further address sport-specific demands, there is a need to explore the core strength performance in elite alpine skiers to determine specific training programmes and optimise sporting performance. Therefore, we aimed to compare trunk strength capacities and flexion/extension core ratios in elite alpine skiers with a matched control group according to gender.

\section{Material and Methods}

\section{Participants}

Strength data of 109 elite alpine skiers (56 females, $22.4 \pm 3.4$ years old; 53 males, $22.1 \pm 3.6$ years old) competing in international speed and technique disciplines of the International Ski Federation (FIS) were collected from 2008 to 2011. All athletes met the qualification criteria for the national alpine ski team of the Austrian Ski Federation. They were grouped into one of the three following training groups by age and performance: junior $(\mathrm{n}=44)$, European Cup $(\mathrm{n}=$ 42) or World Cup ( $n=23)$, which was the highest level. In terms of the exercise background, female and male alpine skiers presented homogeneous conditions. Although the athletes underwent core strength testing more than once throughout the three-year period, only the last preseason test result for each athlete was analysed to guarantee better comparability with the control group. The control group consisted of 47 sport and exercise science students ( 26 females, $23.3 \pm 2.1$ years old; 21 males, $24.6 \pm 1.8$ years old) that were anthropometrically matched according to gender. The participants of the control group were engaged in different recreational sports such as swimming, athletics and team sports (soccer, volleyball). Exclusion criteria for the control group were regular participation in alpine skiing, specific and frequent strengthening of the trunk muscles as well as being part of a national team in any sport. Familiarisation trials were conducted one week prior to testing. Exclusion criteria for the control group were regular strength training three months prior to testing and any back problem two months prior to testing. Subjects of the control group were instructed to avoid vigorous exercise for two days before their test date.

\section{Procedures}

The Institutional Review Board (IRB) of the Department of Sport Science comprising medical doctors and sports scientists reviewed and evaluated the research proposals with a focus on ethics, quality of research, and benefit to the athletes. The athletes were informed of any risks associated with participation in the tests, and written informed consent was obtained before testing began. The study was performed according to the Declaration of Helsinki. Before testing body height was measured using a portable stadiometer (Seca 220, Seca, Germany), and body mass was recorded using the Kistler force plate (Kistler Instrumente AG, Winterthur, Switzerland). Table 1 represents the anthropometric data of the two groups.

Testing was conducted using the biomechanical test and the CON-TREX TP $1000^{\circledR}$ (CMV AG Duebendorf, Switzerland) test- and training system. To establish the test-retest reliability, intraclass correlation coefficients (ICC) were calculated at two different test times (day one and day three) from 29 (14 female, 15 male) athletes from the youth squad of the national skiing team. The calculated ICC values showed high to excellent test-retest reliability of $0.89-0.93$ $(p \leq 0.001)$ and were similar to previous studies from Platzer et al. (2009). CON-TREX human kinetics software permitted data collection. Prior to testing, each participant was required to perform a standardised warm up. To measure the trunk strength, each subject was individually positioned on the dynamometer in a standing position. The alignment between the rotational axis of the dynamometer and the rotational axis of the lumbosacral junction was checked. To avoid additional use of hip muscles, the lower limbs, hip 
and upper body were secured using pads and belts (Figure 1). A gravity correction was made prior to testing. Using the ballistic mode, the first four repetitions of concentric isokinetic flexion and extension contractions at $150 \%$ were performed with submaximal effort $(70-80 \%$ of maximal voluntary contraction). Following a $60 \mathrm{~s}$ rest interval the subjects were instructed to perform three repetitions of maximum effort. The second trial with three repetitions of maximal voluntary contractions was performed after a $60 \mathrm{~s}$ rest interval. The active range of motion (ROM) was set at $60^{\circ}\left(0^{\circ}\right.$ Extension, $60^{\circ}$ Flexion). During the test, consistent verbal motivation was used to minimise potential influences of verbal feedback.

\section{Main outcome measure}

Data of the best result from the two trials were selected for evaluation. The absolute peak torque $(\mathrm{Nm})$, relative peak torque $(\mathrm{Nm} / \mathrm{kg})$, absolute $(\mathrm{W})$ and relative $(\mathrm{W} / \mathrm{kg})$ mean power for flexion and extension and the ratio of flexion/extension (Index) were calculated according to gender. The body mass adjusted peak torques of flexion/extension strength were calculated to allow direct comparison between alpine skiers and controls despite anthropometrical differences.

\section{Statistical Analysis}

Descriptive statistics were calculated and expressed as the means and standard deviation for each variable with the corresponding $99 \%$ confidence interval (CI). The differences across groups were analysed using unpaired Student's ttests. A criterion of $p \leq 0.01$ defined the significance. All statistical analyses were performed using SPSS 19.0 software (SPSS Inc., Chicago, IL).

\section{Results}

Analyses of anthropometric data revealed differences between the groups. Male alpine skiers were significantly older $(p=0.003)$ and heavier $(p<0.001)$ than controls. No differences were found for body height $(p=0.062)$. Female skiers were significantly heavier $(p=0.041)$ than controls, and no differences were found for age $(p$ $=0.193)$ or body height $(p=0.675)$. For all of the measurements and in both study groups, the female participants were significantly weaker than their male counterparts.

\section{Male participants}

Table 2 represents all strength data of male participants according to the group. In both groups, the production of force during extension was higher than that during flexion. The comparison of peak torque indicated characteristic differences between the groups. The t-tests showed that alpine skiers achieved significantly higher strength values in both absolute and relative maximum torque for flexion, extension and mean power. The ratio of trunk flexion and extension was slightly higher in the control group for both, peak torque and mean power, but did not reach statistical significance. The low values from 0.54 to 0.59 suggested weak trunk flexor muscles relative to the extensor group.

\begin{tabular}{|c|c|c|c|c|}
\hline \multirow{2}{*}{\multicolumn{5}{|c|}{$\begin{array}{r}\text { Table } \mathbf{1} \\
\text { Anthropometric data of elite alpine skiers and controls according to gender }\end{array}$}} \\
\hline & & & & \\
\hline \multicolumn{2}{|c|}{ Group } & Age (years) & Body mass (kg) & Height (cm) \\
\hline \multirow{3}{*}{ Alpine skiers } & male $\mathrm{n}=53$ & $22.1( \pm 3.6)$ & $83.8( \pm 5.7)$ & $180.3( \pm 5.6)$ \\
\hline & & & & \\
\hline & female $n=56$ & $22.4( \pm 3.4)$ & $63.7( \pm 5.4)$ & $166.7( \pm 4.9)$ \\
\hline \multirow{3}{*}{ Controls } & male $\mathrm{n}=21$ & $24.6( \pm 1.8)$ & $76.7( \pm 7.2)$ & $178.7( \pm 5.0)$ \\
\hline & & & & \\
\hline & female $n=26$ & $23.3( \pm 2.1)$ & $61.6( \pm 6.6)$ & $167.2( \pm 6.1)$ \\
\hline
\end{tabular}




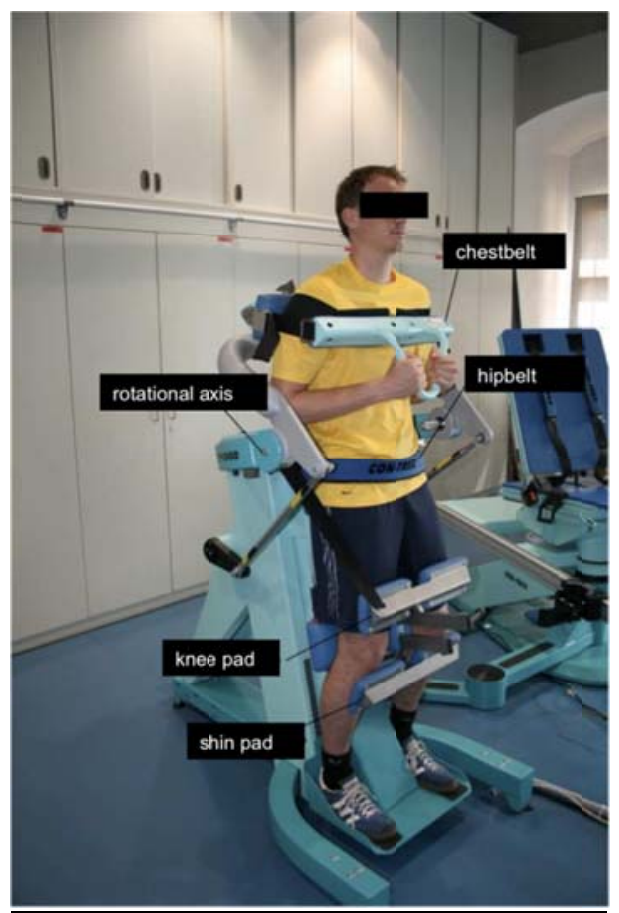

Figure 1

Positioning in the dynamometer

Table 2

Mean and standard deviation (SD) of the strength characteristics in male participants

\begin{tabular}{|c|c|c|c|c|c|c|c|}
\hline & Movement & Variable & Group & Mean $( \pm$ SD) & $\begin{array}{l}\text { Lower } \\
99 \% \text { CI }\end{array}$ & $\begin{array}{c}\text { Upper } \\
99 \% \text { CI }\end{array}$ & $p$ \\
\hline \multirow{10}{*}{ 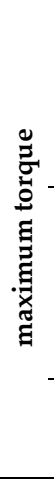 } & \multirow{4}{*}{ Flexion } & \multirow{2}{*}{ absolute (Nm) } & skiers & $204.9( \pm 28.6)$ & 146 & 270 & \multirow{2}{*}{$<0.001$} \\
\hline & & & controls & $173.6( \pm 27.3)$ & 113 & 213 & \\
\hline & & \multirow{2}{*}{ relative $(\mathrm{Nm} / \mathrm{kg})$} & skiers & $2.44( \pm 0.30)$ & 1.9 & 3.2 & \multirow{2}{*}{0.003} \\
\hline & & & controls & $2.32( \pm 0.42)$ & 1.6 & 2.9 & \\
\hline & \multirow{4}{*}{ Extension } & \multirow{2}{*}{ absolute (Nm) } & skiers & $378.2( \pm 54.4)$ & 267 & 492 & \multirow{2}{*}{$<0.001$} \\
\hline & & & controls & $299.1( \pm 47.9)$ & 215 & 404 & \\
\hline & & \multirow{2}{*}{ relative $(\mathrm{Nm} / \mathrm{kg})$} & skiers & $4.53( \pm 0.65)$ & 3.5 & 6.1 & \multirow{2}{*}{0.001} \\
\hline & & & controls & $4.11( \pm 0.52)$ & 2.8 & 4.9 & \\
\hline & \multirow{2}{*}{ Flex/Ex } & \multirow{2}{*}{ ratio (Index) } & skiers & $0.56( \pm 0.09)$ & 0.35 & 0.88 & \multirow{2}{*}{0.134} \\
\hline & & & controls & $0.59( \pm 0.12)$ & 0.40 & 0.94 & \\
\hline \multirow{10}{*}{ 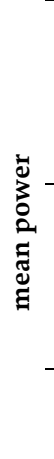 } & \multirow{4}{*}{ Flexion } & \multirow{2}{*}{ absolute (W) } & skiers & $137.8( \pm 19.1)$ & 95 & 181 & \multirow{2}{*}{$<0.001$} \\
\hline & & & controls & $118.1( \pm 19.9)$ & 74 & 146 & \\
\hline & & \multirow{2}{*}{ relative (W/kg) } & skiers & $1.79( \pm 0.24)$ & 1.3 & 2.1 & \multirow{2}{*}{0.001} \\
\hline & & & controls & $1.61( \pm 0.31)$ & 1.0 & 2.0 & \\
\hline & \multirow{4}{*}{ Extension } & \multirow{2}{*}{ absolute (W) } & skiers & $259.2( \pm 38.7)$ & 183 & 344 & \multirow{2}{*}{$<0.001$} \\
\hline & & & controls & $208.6( \pm 33.4)$ & 155 & 288 & \\
\hline & & \multirow{2}{*}{ relative (W/kg) } & skiers & $3.18( \pm 0.37)$ & 2.2 & 4.2 & \multirow{2}{*}{$<0.001$} \\
\hline & & & controls & $2.80( \pm 0.34)$ & 1.9 & 3.4 & \\
\hline & \multirow{2}{*}{ Flex/Ex } & \multirow{2}{*}{ ratio (Index) } & skiers & $0.54( \pm 0.09)$ & 0.33 & 0.84 & \multirow{2}{*}{0.145} \\
\hline & & & controls & $0.57( \pm 0.12)$ & 0.41 & 0.89 & \\
\hline
\end{tabular}




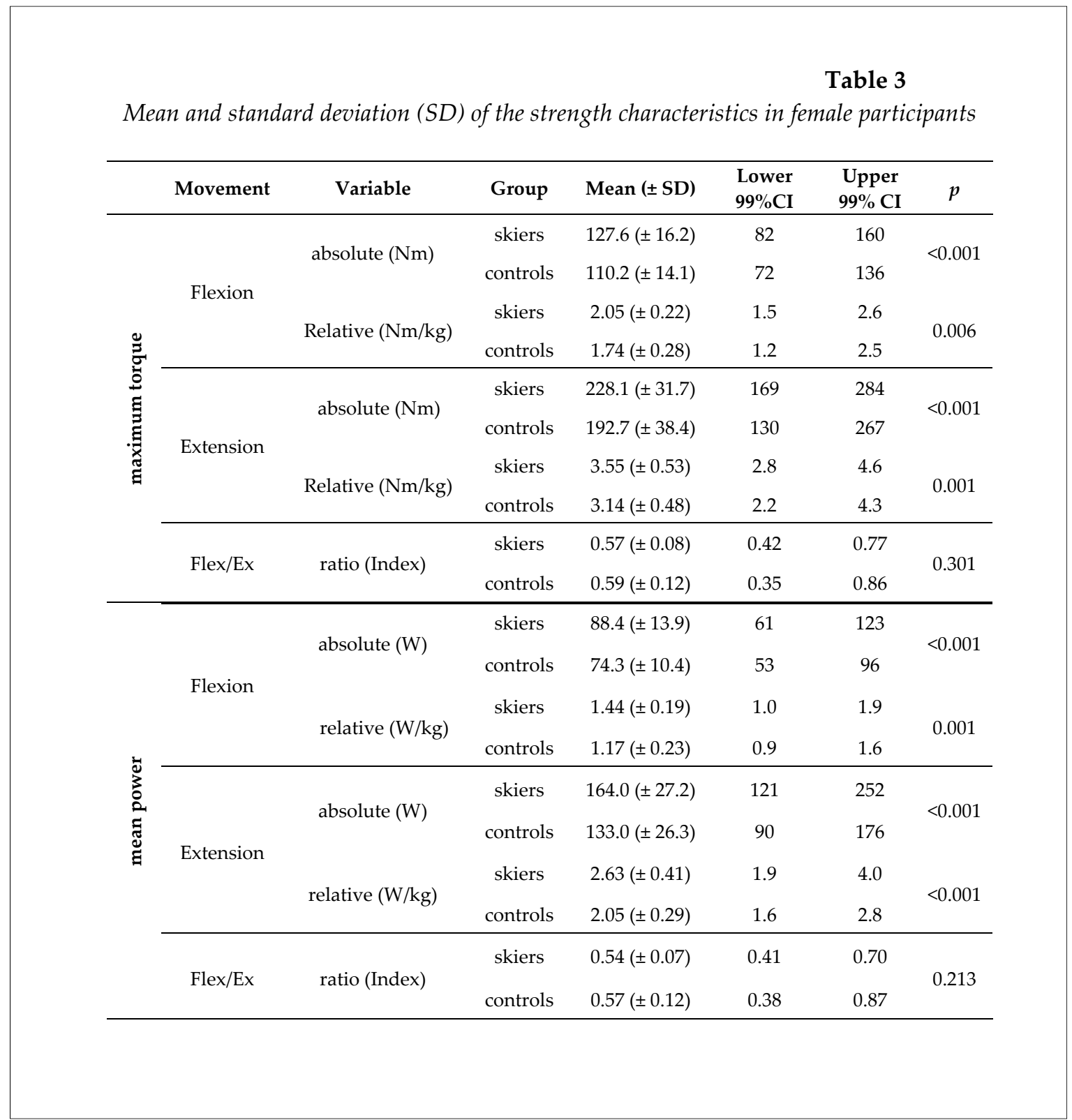

\section{Female participants}

The trunk strength data of female participants is shown in Table 3. As with male participants, the females were stronger during extension than flexion independent of groups. Analysis of the peak torque and average power revealed that alpine skiers were constantly stronger than the controls. No differences were found for the ratio of trunk flexion or extension. Similar to male athletes, the low index of trunk flexor to extensor strength indicated stronger extensor muscles.

\section{Discussion}

Sufficient trunk strength is a basic requirement of athletic performance and has great relevance for sport-specific profiling to maintain an optimal posture and to lower excessive loading on passive structures. Investigations of trunk strength in elite athletes are rare, and to date, no studies exist for alpine skiing. The principal finding of the current study was that irrespective of gender, all strength values obtained by alpine skiers were significantly higher than those of the control group. Similar to previous findings in the athletic population (Baur et al., 2010; Ezechieli et al., 2013; McGregor et al., 2004), trunk strength of male athletes was higher than that of females in both groups. Female trunk extension strength was approximately $70-72 \%$ that of men. These values are slightly higher than those of other studies, 
which investigated isokinetic trunk strength in sedentary subjects (Dvir et al., 2001). Isokinetic measurements have often been used to determine the generation of force in elite athletes (Baur et al., 2010; Ellenbecker and Roetert, 2004). In contrast to isometric measurements, isokinetic measurements allow an investigation of the force-velocity relationship between different athletes. The methods used for the present study had been determined to be reliable and valid in a similar setting (Baur et al., 2010; Guilhem et al., 2014; Karatas et al., 2002; Mueller et al., 2012). The finding that force production during flexion was lower than that during extension movements in both groups agrees with the findings of Baur et al. (2010) and McGregor et al. (2004), although contradicts the results of Thompson et al. (1985). Thompson et al. (1985) reported that extensor muscles dominated at low speed $\left(30^{\circ}-60^{\circ} / \mathrm{s}\right)$, while flexors dominated at high speed $\left(120^{\circ}-150^{\circ} / \mathrm{s}\right)$. Differences in the results may be due to the different characteristics of the subjects and the velocity of isokinetic testing. Although the use of different velocities limits the comparison with other research, it must be noted that a slow velocity is not indicative of the movements during alpine skiing. Comparable studies of isokinetic trunk measurements in athletes used lower velocities. However, Baur et al. (2010) compared isokinetic trunk strength of race-car drivers at $60 \% \mathrm{~s}$ and $120 \%$ s and stated that the results were similar irrespective of velocity. It was further concluded that one test speed was enough to evaluate reliability and validate muscle strength performance (Dvir and Keating, 2001). The velocity of $150 \%$ s used in the present study is considered very high, which may have affected the recruitment pattern of the trunk muscles. Van Damme et al. (2013) showed that increased velocity led to a higher activity of deep local stabilising muscles compared to the larger superficial global muscles. In contrast to the amount of slow-twitch fibres in the local muscle system, the presence of fast-twitch fibres is higher in global muscle systems (Akuthota et al., 2008). As suggested by Newton et al. (1997), a faster movement requires less force production and therefore, a smaller proportion of the motor unit pool of muscle fibres. Alpine skiing is characterised by fast movements and a very high level of muscle recruitments. Electromyography measurements during giant slalom and slalom events showed a high activity of leg and trunk muscles (Hintermeister et al., 1995). Consequently, alpine skiers are engaged in strength training of large volume for both, leg and trunk muscles, which explains the higher peak values of trunk strength compared to that of the control group. Alpine skiers were heavier than the controls and the correction for body weight showed differences in relative peak and mean values. The relationship between weight and isokinetic trunk performance has been recently discussed. Cowley et al. (2009) showed that this relationship was apparently stronger in young men than in women, but the results of the present study indicated no gender differences. When considering the ratio between flexor and extensor muscles, strong dominance of extensor muscles was found in both groups. The concept of muscle imbalance had been previously characterised by different authors who described the ratio of agonist and antagonist muscles acting over a joint. In alpine skiing recommendations were provided for a balanced hamstring to quadriceps strength ratio and leg strength (Neumayr et al., 2003). The reliability of the most common strength imbalance ratios for leg muscles was measured using isokinetic testing (Impellizeri et al., 2007). However, for trunk muscles, there is a lack of research examining the required sport specific strength index. Although all strength values differed significantly between groups, no differences were found for the extension/flexion index, which indicates that the ski specific training showed no influence on the trunk ratio. These findings are similar to those of Kort and Hendriks (1992) who stated that the ratios between cyclists and judo athletes and the values found for the control subjects appeared to be the same. In the present study, both groups indicated a relatively low ratio from 0.54-0.59, which represented a high strength level of trunk extensor muscles relative to flexor muscles. Mueller et al. (2012) stated that the trunk extension to flexion ratio was lower in rowers with higher performance indicating strong flexor muscles. In contrast to rowing, where an asymmetric nature has been speculated to lead to muscle asymmetries, alpine skiing requires a symmetric nature for flexion and extension. In the bend forward position, the back muscles need to 
generate high forces to counteract the flexion movement (Tesch et al., 1995). Alpine skiers are exposed to excessive loading of the spine. It can be assumed that predominately eccentric muscle actions are necessary to counteract passively induced loading during skiing in both, flexor and extensor muscles to generate force and balance during unanticipated situations on the ski slope. The combination of frontal bending, lateral bending and torsion in the loaded trunk of alpine skiers has been identified as a risk of overuse injuries to occur in the lumbar spine (Spörri et al., 2015). In addition, radiographic investigations in young elite skiers revealed a significantly higher rate of anterior endplate lesions than that of the control subjects (Rachbauer et al., 2001). Consequently, the importance of an optimal flexion and extension ratio has implications for the development of measurement and training protocols. Gibbons et al. (2001) proposed a model where stabilizers (i.e. M. obliquus abdominis externus and internus) and mobilizers (i.e. M. rectus abdominis) were distinguished. It can be assumed that during skiing stabilizers contract eccentrically to control movement and rotation of the trunk, while mobilizers act predominantly as shock absorbers during landing and on bumpy slopes. Therefore, prevention strategies specific to alpine skiing should focus on an optimal flexionextension ratio and testing modalities must include an examination of muscle strength of the rectus abdominis and obliquus abdominis.

It should be noted that the present study does include some limitations. The results allow conclusions for each athlete to generate force in the trunk muscles in a fixed testing position. However, there is limited evidence for the potential of trunk stability during athletic participation in high-speed events. The maximum strength of flexion and extension muscles of the trunk is only one component of core stability, motor control and the strength of the lumbopelvic-hip complex needs to be considered as well (Hibbs et al., 2008; Leetun et al., 2004). An additional area of concern is the limited test approach using only isokinetic measurements to evaluate the peak torque. It has been proposed that overuse reactions of the back and low back pain, in particular, are caused by impairment of strength endurance and not maximum strength capacities. In terms of muscle fatigue, the current literature has shown that an isometric hold seems to be a more efficient way of achieving strength endurance than isokinetic flexion and extension (Moreau et al., 2001). Furthermore, alpine skiing is characterised by a combination of force in the horizontal, sagittal and transversal planes. The present test is merely performed in a sagittal plane. The use of a flexion-rotation trunk test as first described by Brotons-Gil et al. (2013) may satisfy sport specific demands. These claims need to be considered to further investigate the effect of trunk strength on both, injury prevention and performance improvements in elite alpine skiers.

\section{Acknowledgements}

This study received no specific grant from any funding agency, commercial or not-for-profit sectors. The authors thank the athletes and control subjects for their participation in the study.

\section{References}

Akuthota V, Ferreiro A, Moore T, Fredericson M. Core stability exercise principles. Curr Sports Med Rep, 2008; 7: 39-44

Baur H, Müller S, Pilz F, Mayer P, Mayer F. Trunk extensor and flexor strength of long-distance race car drivers and physically active controls. J Sport Sci, 2010; 28: 1183-1187

Bergstrøm KA, Brandseth K, Fretheim S, Tvilde K, Ekeland A. Back injuries and pain in adolescents attending a ski high school. Knee Surg Sports Traumatol Arthrosc, 2004; 12: 80-85

Brotons-Gil E, Garcia-Vaquero M, Peco-Gonzales N, Vera-Garcia FJ. Flexion rotation trunk test to assess abdominal muscle endurance: reliability, learning effect and sex differences. J Strength Cond Res, 2013; 27: $1602-1608$ 
Cowley PM, Fitzgerald S, Sottung K, Swensen T. Age, weight and the front abdominal power test as predictors of isokinetic trunk strength and work in young men and women. J Strength Cond Res, 2009; 23: $915-925$

Dvir Z, Keating J. Reproducibility and validity of a new test protocol for measuring isokinetic trunk extension strength. Clin Biomech, 2001; 16: 627-630

Ellenbecker TS, Roetert EP. An isokinetic profile of trunk rotation strength in elite tennis players. Med Sci Sports Exerc, 2004; 36: 1959-1963

Ezechieli M, Siebert CH, Ettinger M, Kieffer O, Weißkopf M, Miltner O. Muscle strength of the lumbar spine in different sports. Tech Health Care, 2013; 21: 379-386

Gibbons SGT, Comerford MJ. Strength versus stability: part 1. Concepts and terms. Orthop Division Rev, 2001; 2: $21-27$

Guilhem G, Giroux C, Couturier A, Maffiuletti N.A. Validity of trunk extensor and flexor torque measurements using isokinetic dynamometry. J Electromyogr Kines, 2014; 24: 986-993

Hibbs AE, Thompson KG, French D, Wrigley A, Spears S. Optimizing performance by improving core stability and core strength. Sports Med, 2008; 38: 995-1008

Hintermeister RA, O'Connor DD, Dillmann CJ, Suplizio CL, Lange GW, Steadman JR. Muscle activity in slalom and giant slalom skiing. Med Sci Sports Exerc, 1995; 27: 315-322

Hydren JR, Volek JS, Maresh CM, Comstock BA, Kraemer WJ. Review of Strength and Conditioning for Alpine Ski Racing. Strength Cond J, 2013; 35: 10-28

Karatas GK, Gogus F, Meray J. Reliability of isokinetic trunk muscle strength measurement. Am J Phys Med Rehabil, 2002; 81: 79-85

Kort HD, Hendriks MD. A comparison of selected isokinetic trunk strength parameters of elite male judo competitors and cyclists. JOSPT, 1992; 16: $92-96$

Hildebrandt C, Raschner C. Traumatic and overuse injuries among elite adolescent alpine skiers. Int SpoMed J, 2013; 14: 245-255

Impellizzeri FM, Bizzini M, Rampinini E, Cereda F, Maffiuletti NA. Reliability of isokinetic strength imbalance ratios measured using the Cybex NORM dynamometer. Clin Physiol Funct Imaging, 2008; 28: $113-119$

Leetun DT, Ireland ML, Willson JD, Ballantyne BT, Davis IM. Core Stability Measures as Risk Factors for Lower Extremity Injury in Athletes. Med Sci Sports Exerc, 2004; 36: 926-934

McGregor A, Hill A, Grewar J. Trunk strength pattern in elite rowers. Isokinetic Exerc Sci, 2004; 12: 253-261

Mueller S, Stoll J, Mueller J, Mayer F. Validity of isokinetic trunk measurements with respect to healthy adults, athletes and low back pain patients. Isokinetic Exerc Sci, 2012; 20: 255-266

Moreau CE, Green BN, Johnson CD, Moreau SR. Isometric back extension endurance tests: a review of the literature. J Manipulative Physiol Ther, 2001; 24: 110-122

Neumayr G, Hoertnagl H, Pfister R, Koller A, Eibl G, Raas E. Physical and physiological factors associated with success in professional alpine skiing. Int J Sports Med, 2003; 24: 571-575

Newton R, Murphy A, Humphries B, Wilson G, Kraemer W, Häkkinen K. Influence of load and stretch shortening cycle on the kinematics, kinetics and muscle activation that occurs during explosive upperbody movements. Eur J Appl Physiol, 1997; 75: 333-342

Platzer HP, Raschner C, Patterson C, Lembert S. Comparison of physical characteristics and performance among elite snowboarders, J Strength Cond Res, 2009; 23: 1427-1432

Rachbauer F, Sterzinger W, Eibl G. Radiographic abnormalities in the thoracolumbar spine of young elite skiers. Am J Sports Med, 2001; 29: 446-449

Raschner C, Platzer HP, Patterson C, Werner I, Huber R, Hildebrandt C. The relationship between ACL injuries and physical fitness in young competitive ski racers: a 10-year longitudinal study. Br J Sports 
Med, 2012; 46: 1065-1071

Schmidt CP, Zwingenberger S, Walther A, Reuter U, Kasten P, Seifert J, Günther KP, Stiehler M. Prevalence of Low Back Pain in Adolescent Athletes - an Epidemiological Investigation. Int J Sports Med, 2014; 35: 684-689

Spörri J, Kröll J, Haid C, Fasel B, Müller E. Potential Mechanisms Leading to Overuse Injuries of the Back in Alpine Ski Racing. Am J Sports Med, 2015; 43: 2042-2048

Tesch PA. Aspects on muscle properties and use in competitive alpine skiing. Med Sci Sport Exerc, 1995; 27: 310-314

Thompson NN, Gould JA, Davies GJ, Ross DE, Price S. Descriptive measures of isokinetic trunk testing. JOSPT, 1985; 7: 43-49

Van Damme BB, Stevens VK, Van Tiggelen DE, Duvigneaud NN, Neyens E, Danneels LA. Velocity of isokinetic trunk exercises influences back muscle recruitment patterns in healthy subjects. $J$ Electromyogr Kines, 2013; 23: 378-386

Young WK, d'Hemecourt PA. Back pain in adolescent athletes. Phys Sportsmed, 2011; 39: 80-89

\section{Corresponding author:}

\section{Carolin Hildebrandt, PhD}

Department of Sport Science, University of Innsbruck

Fuerstenweg 185, 6020 Innsbruck, Austria

Phone: +43 (0) 51250745907

Fax: +43 (0) 51250745999

E-Mail: Carolin.Hildebrandt@uibk.ac.at 